\title{
Understanding swarm earthquakes in Southeast Aceh, Sumatra
}

\author{
Andrean V. H. Simanjuntak ${ }^{1,3}$, Djati C. Kuncoro ${ }^{1}$, Irwandi Irwandi ${ }^{2,3}$ and Umar Muksin ${ }^{2,3}$ \\ ${ }^{1}$ Badan Meteorologi Klimatologi dan Geofisika (BMKG), 22123 Aceh Besar, Aceh, Indonesia \\ ${ }^{2}$ Department of Physics of Universitas Syiah Kuala (USK), 22122 Banda Aceh, Aceh, Indonesia \\ ${ }^{3}$ Tsunami Disaster and Mitigation Hazard Center (TDMRC), Universitas Syiah Kuala (USK), 22122 Banda Aceh, Aceh, Indonesia
}

\begin{abstract}
The cause of the swarm earthquakes occurring from September until November 2020 remains unclear. The swarm activities are close to the Tripa active fault but also close to Mt. Bendahara. This study offers the analysis of seismic $\mathrm{P}$ and $\mathrm{S}$ wave arrivals and relocate the hypocenter of the swarm. We analysed the hypocentre distribution that recorded by Badan Meteorologi Klimatologi dan Geofisika (BMKG) from July 2020 to January 2021. The arrival of P and S-wave from 103 events was used obtain 1-D seismic velocity model. The earthquake used for this study consisted of at least 6 phases of seismic arrivals with the azimuthal gap angle less than 180 degree. The different velocities occurred in the upper and lower of the crustal thickness of $0-40 \mathrm{~km}$. The Vp values are about $5.0-7.0 \mathrm{~km} / \mathrm{s}$ and $3.0-5.0 \mathrm{~km} / \mathrm{s}$ for Vs value while the $\mathrm{Vp} / \mathrm{Vs}$ ratio are ranging from 1.5 to 1.7 . Our preliminary results indicate that the potential swarm activities near to Mt. Bandahara maybe triggered by an unknown fault activity as no volcanic activity was reported.
\end{abstract}

\section{Introduction}

The September-October 2020 swarm activities in the northern part of Southeast Aceh (Figure 1) are categorized as a rare event since there was no previous being recorded before. The swarm activities may be undetected due to limited seismic sensor in the Aceh province. The first assumption of the swarm activities in Southeast Aceh was generated by the Tripa segment activities. However, intense swarm activities with a sequence of $>100$ occurring events might had been influenced by volcanic activities because it is closed to Mt. Bandahara.

Historically, the Tripa fault has generated several earthquakes in 1990 with M 6.8 and in 1996 with M 7.2 $[1,2,3,4]$. Another major earthquake occurred in the northern part of the Tripa fault on July 2nd, 2013 with magnitude of M 6.2 which was strongly felt by the local people in the Southeast Aceh $[3,4,5,6]$. Local people reported that they felt the swarm in the I - III MMI which was related to the seismic hazard investigation.

Irwandi et al., [7] proposed an updated seismic hazard model for the Southeast Aceh region in order to understand the probability of seismic hazard with an exceeded limit percentage of $2 \%$ and $10 \%$ for 50 years without including the swarm activities.

The percentage and the year probability were chosen to calculate the PGA (Peak Ground Acceleration) map on the bedrock structure. The amplification results show that the PGA can reach $0.9 \mathrm{~g}$ and $1.5 \mathrm{~g}$ for the exceeded limit of $10 \%$ and $2 \%$ respectively [7].

The amplification is likely to be exceeded for 50 years with the ratio reaching 1.6 times in areas of densely populated people in Kutacane. It is also important to conduct a more suitable seismic hazard model in the future by including the earthquakes from the swarm activities $[9,10,11,12]$. The detailed study of swarm needs to be conducted in order to understand the cause of the swarm.

In this research, we tried to analyse the earthquake arrival time of the P- and S-wave of the swarm. The arrival time data was used to determine an optimum 1D seismic velocity model. The earthquakes were simultaneously relocated. The results of the relocation and the seismic velocity model may provide a preliminary explanation of the swarm activities.

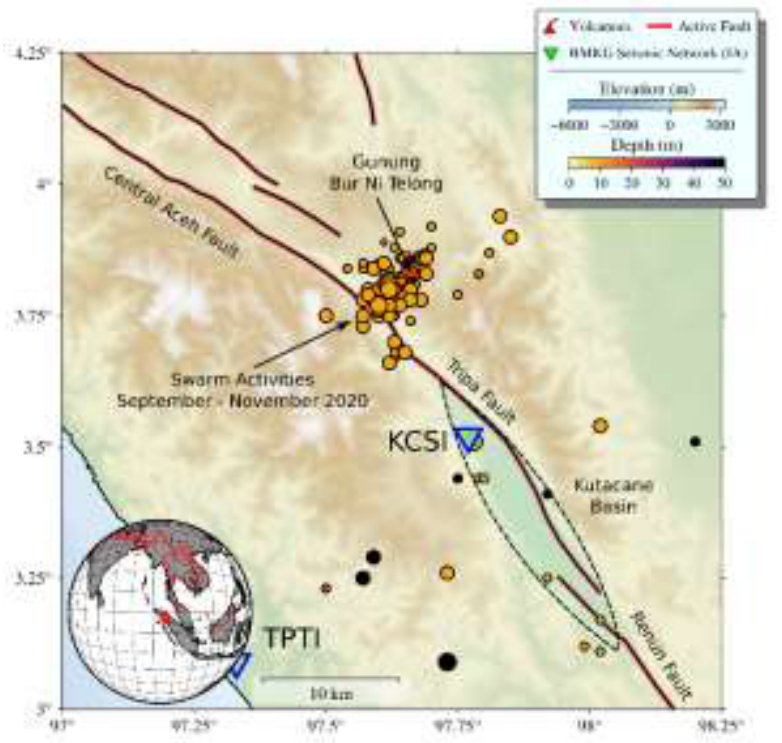

Fig. 1. The tectonic system and the seismic activities ... between September to October 2020 in the Southeast Aceh region. The swarm activities were located close to the Tripa fault and beneath Mt. Bandahara. About 103 events were recorded by the seismic network in the northen part of Sumatra with KCSI station has more arrival times data. 


\section{Data and Method}

\subsection{Data Observation}

The Meteorological, Climatological, and Geophysical Agency has operated 20 recording seismometers which have been established since 2009 [8, 10]. BMKG, as the official agency of earthquake monitoring, operates various seismometers to record the earthquake waveform and routinely pick the $\mathrm{P}$ and $\mathrm{S}$ phase arrivals to determine and disseminate the earthquakes quickly $[13,14]$.
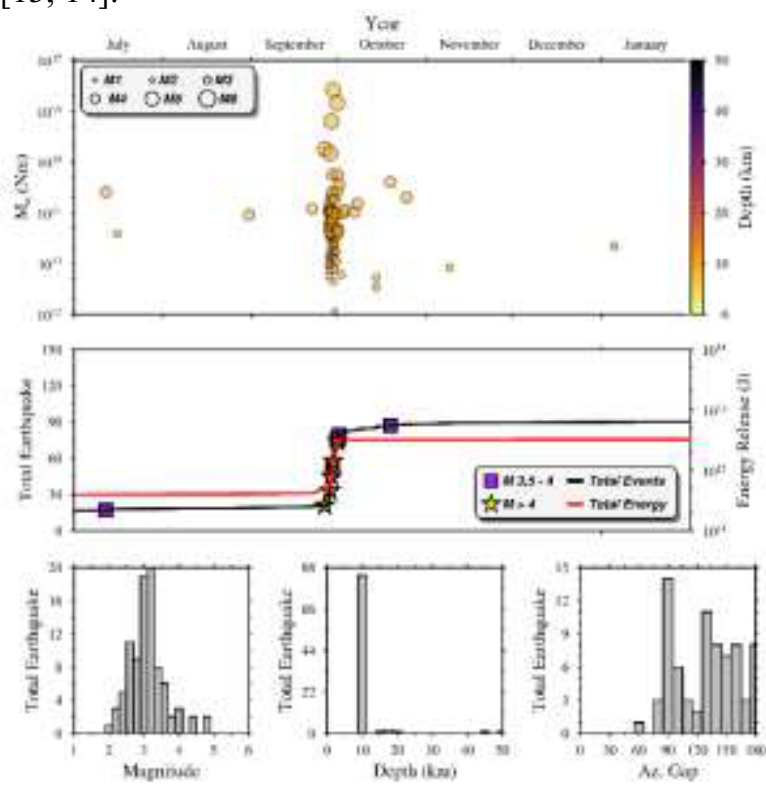

Fig. 2. Temporal graphic of swarm activities in the study area (upper panel). The estimation of seismic energy accumulation that was released from swarm activities around $10^{12}-10^{13} \mathrm{~J}$ (middle panel). The distribution of magnitude, depth and azimuthal gap for all events were selected by optimum criteria to obtain 1-D seismic velocity in the study area (bottom panel).

For this research, we analysed the arrival times of body waves ( $\mathrm{P}$ and $\mathrm{S}$-waves) recorded by 20 seismic stations in the northern part of Sumatra from July 2020 to January 2021 with the total of 103 events. To initiate a unique solution, in this study we used the data of events with depth of less than $50 \mathrm{~km}$ according to the BMKG catalogue This means that all earthquakes location occurred in the crust. Furthermore, we firstly choose events recorded by at least 6 seismic arrivals (P or S waves) with the azimuthal gap angle $<180^{\circ}$ and the distance between earthquakes and stations were less than $5^{\circ}(<500 \mathrm{~km})$.

For statistical purposes, time series analysis (Figure 2) was applied to figure out the temporal variation in the study area. The earthquake distribution underwent a significant change in September 2020 while no activities occurred in the previous month. The total seismic energy release was around $10^{11}-10^{12}$ Joule and the accumulation of energy was up to $10^{13}$ Joule. The total of energy release was not bigger than the common crustal earthquakes release. The reason might be due to the absence of fault activities [15].

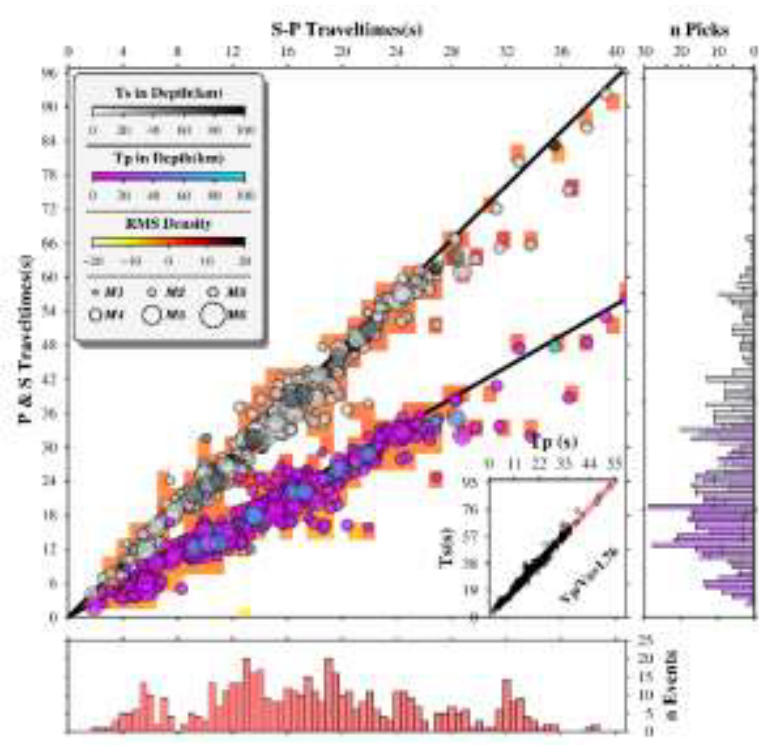

Fig. 3. The interactive of the Wadati diagram describing the distribution of arrival times of the P-phase (grey circle) and the S-phase (purple circle). The rms values were set for both phases in from -20 to 20 seconds which might had been adapted from the global velocity model IASP-91. The ratio of $\mathrm{Vp} / \mathrm{Vs}$ was 1.76 . The total events were 103 with the total of Pphase picks were 687 and S-phase were 321 with the distance of $0^{\circ}-5^{\circ}$ and the azimuthal gap $<180^{\circ}$.

\subsection{Coupled-Velocity Relocation}

The hypocenter distribution of the swarm was nonlinearly influenced by velocity model and the distribution of seismic stations $[2,3]$. The semi nonlinear approach was among several earthquake relocation that often used. The method of the coupledvelocity relocation was chosen to relocate the events and simultaneously determine the velocity model. $[4,8,13$, 14].

The semi nonlinear approach is useful to relocate a fixed initial regional or local earthquake which trapped on a specific depth. In this study, the initial hypocentres data from BMKG shows a fixed depth solution based on the global velocity model [14].

To improve the accuracy of the hypocentre locations, an appropriate 1-D seismic velocity model was needed. We used the VELEST program [6] to determine a new velocity model that compatible with the hypocentres distribution and the tectonic system in the study area.

A total of 64 different initial velocity models and locations of earthquakes were used in this study. Subsequently, the simultaneous inversion was applied for each initial velocity model. The inversion result, including the new hypocenter locations and the 1D velocity model of each input model was compared to obtain best solution. The result with the smallest RMS value (see Fig. 5) and consistently decrease in each iteration was chosen as the best 1-D velocity model. Furthermore, the new hypocentres were also accepted as the final earthquake locations.

The result was illustrated in a unique 1-D velocity model that is suitable with the new hypocentres location 
and correct the delayed time in all recording station. The selected data of an event used for the inversion analysis were limited to those with a minimum of six phases and the azimuthal gap angle less than $180^{\circ}$.

\section{Result and Discussion}

The 81 velocity models (Vs, Vs and Vp/Vs models) used in the inversion are shown in Figure 4.

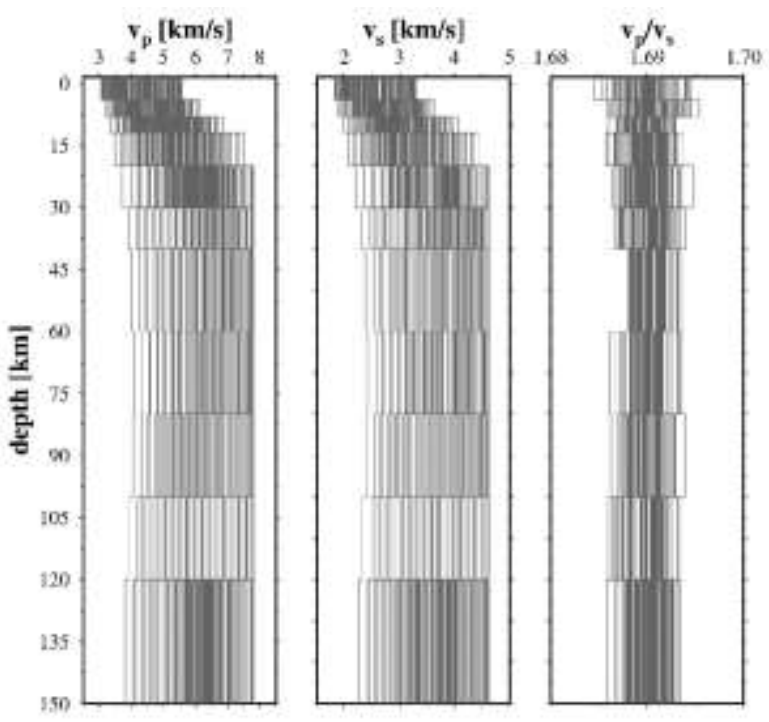

Fig. 4. The total of 81 initial 1D velocity models was appointed as the first model that creates simultaneous inversion (a) Vp model, (b) Vs model and (c) Vp/Vs ratio.

Each model was inverted by 30 iteration to generate the final solution. All initial provided more realistic with models of $\mathrm{Vp}, \mathrm{Vs}$ and the ratio of $\mathrm{Vp} / \mathrm{Vs}$. Simultaneously, the hypocenter locations and the station corrections were also obtained.

Initial models produced a new model that relevant and suitable with the hypocenter distribution. The models were randomly chosen to be within the boundary corridor that indicated by dashed line in Figure 5. All imposed models were convergent to produce the best velocity model with lowest rms values.

The average rms value for all imposed models were smaller than 1.0. The best velocity models are represented by the red lines in Figure 5, which has the lowest rms values and the convergence solution.

The depth variation of the earthquakes in figure 5 is significantly changing from the fixed depth to the different depth. From this research, we found the optimum velocity model that relevant the study area around the Mt. Bandahara.

The velocity model changes in accordance to the increasing depth. It is based on the depth level of each layer. The model should be further modified into the 3$\mathrm{D}$ model for a clear depiction of different seismic velocity model in each layer as well as to explain the lateral heterogeneity beneath an active system $[3,4,13$, $16,17]$.

The 1-D model can also be used as the velocity reference to conduct an earthquake analysis in Southeast Aceh, such as the inversion mechanism [6] and double difference relocation. The shallow depth is categorized as the active cluster since most hypocentres shallow. The shallow depth earthquake is considered as higher risk to building damages [7]. Special attention regarding the soil properties in areas where swarm can be felt by the local people should be studied further in order to reduce the earthquake risk $[11,14,17]$. The 1$\mathrm{D}$ velocity model can be a useful parameter to calculate the NDSHA [7], generate the focal mechanism [6, 15], tomography [3], conducting a realistic seismic map for important subsurface information $[5,18]$ and detecting precise swarm activities [20].

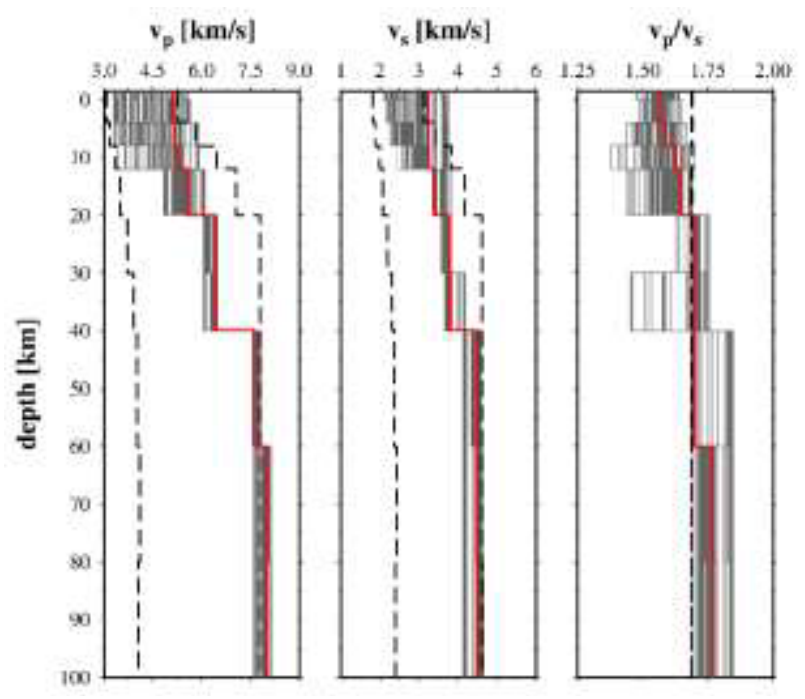

Fig. 5. The 1D velocity model after 30 iterations Vp model, Vs model, and Vp/Vs model. The red lines is the best solution with the smallest RMS values.

\section{Conclusion}

The swarm activities in 2020 in the northern part of Southeast Aceh may be caused by volcanic activities or shallow tectonic swarm. With the total of P-phase picks of 687 and S-phase 321, we successfully generated the optimum 1D velocity model by applying the simultaneous inversion with 81 initials models that converged to a unique final model. Different velocities are located in the upper to the lower level of the crust area with depth of $0-40 \mathrm{~km}$. The $\mathrm{Vp}$ values range between $5.0-7.0 \mathrm{~km} / \mathrm{s}$ and $3.0-5.0 \mathrm{~km} / \mathrm{s}$ for $\mathrm{Vs}$ whereas the $\mathrm{Vp} / \mathrm{Vs}$ ratio is 1.5 to 1.7 . Our preliminary results figure the swarm activities may be triggered by an unknown active fault since there was no indication of volcanic activities in the area.

\section{References}

1. Pasari, S., Simanjuntak, A. V., Mehta, A., Sharma, Y. Pure and Applied Geophysics, 1-18. (2021)

2. Muksin, U., Bauer, K., \& Haberland, C. Journal of volcanology and geothermal research, 260, 27-42. (2013). 
3. Muksin, U., Bauer, K., Muzli, M., Ryberg, T., Nurdin, I., Masturiyono, M., Weber, M. Journal of Asian Earth Sciences, 171, 20-27. (2019).

4. Muksin U, Haberland C, Nukman M, Bauer K, $\&$ Weber M. Journal of Asian Earth Sciences. 2014. 96: 123-131. (2014)

5. Rusydy, I., Idris, Y., Muksin, U., Cummins, P., \& Akram, M. N. Geoenvironmental Disasters, 7(1), 1-16. (2020).

6. Qadariah, Q., Simanjuntak, A. V., Umar, M. Journal of Aceh Physics Society, 7(3), $127-$ 132. (2018).

7. Irwandi, I., Muksin, U., Simanjuntak, A. V. In IOP Conference Series: Earth and Environmental Science (Vol. 630, No. 1, p. 012001). IOP Publishing. (2021).

8. Simanjuntak, A. V., Muksin, U., Setiawan, Y. In IOP Conference Series: Earth and Environmental Science (Vol. 273, No. 1, p. 012021). IOP Publishing. (2019, June).

9. Pasari, S., Simanjuntak, A. V., Sharma, Y. Geoscience Letters, 8(1), 1-13. (2021)

10. Pasari, S., Simanjuntak, A. V., Mehta, A., Sharma, Y. Natural Hazards, 1-13. (2021).

11. Julius, A. M., \& Widana, I. D. K. K. In IOP Conference Series: Earth and Environmental Science (Vol. 708, No. 1, p. 012106). IOP Publishing. (2021, April).

12. Julius, A. M., Pribadi, S., \& Muzli, M. In IOP Conference Series: Earth and Environmental Science (Vol. 132, No. 1, p. 012012). IOP Publishing. (2018, March).

13. Muksin, U., Rusydy, I., Erbas, K., \& Ismail, N. In Journal of Physics: conference series (Vol. 1011, No. 1, p. 012031). IOP Publishing. (2018, April).

14. Simanjuntak, A. V., Sihotang, N., Kuncoro, D. C., Irwandi, I. In Journal of Physics: Conference Series (Vol. 1811, No. 1, p. 012123). IOP Publishing. (2021, March).

15. Daniarsyad, G., Sianipar, D., Heryandoko, N., \& Priyobudi, P. Pure and Applied Geophysics, 1-13. (2021).

16. Muzli, M., Umar, M., Nugraha, A. D., Bradley, K. E., Widiyantoro, S., Erbas, K, Jousset, P., Wei, S. (2018). Seismological Research Letters, 89(5), 1761-1772.

17. Kissling E., Ellsworth W., Eberhart-Phillips D., Kradolfer U. 1994. Journal of Geophysical Research: Solid Earth (1978).

18. Simanjuntak, A. V., Muksin, U., \& Sipayung, R. M. In Journal of Physics: Conference Series (Vol. 1116, No. 3, p. 032033). IOP Publishing. (2018, December).

19. Idris, Y., Cummins, P., Rusydy, I., Muksin, U., Syamsidik, Habibie, M. Y., \& Meilianda, E. Journal of Earthquake Engineering, 1-18. (2019).
20. Hendriyana, A., Bauer, K., Muksin, U., \& Weber, M. Geophysical Journal International, 213(2), 952962. (2018). 